$1^{\circ}$ des phénomènes très nets d'autotomie; $2^{\circ}$ des phénomènes de régénération après amputation spontanée.

A un membre normal à tarse pentamère succède un membre à tarse tétramère. C'est donc une nouvelle vérification de la loi des régénérations hypotypiques (A. Giard).

Constaté déjà chez Phyllium siccifolium, Raphiderus scabrosus, Monandroptera inuncans et Eurycantha horrida, le processus de régénération tétramérique, après autotomie, doit se produire chez tous les Phasmides.

\title{
Communications.
}

\section{Description de deux Réduviides nouveaux [HÉMIPT.]}

Par le $\mathrm{D}^{\mathrm{r}}$ E. Bergroth.

Apiomerus immundus n. sp. - Niger, brevius pilosus, lobo postico pronoti hemelytrisque luride testaceis, membrana sparsim fusco-guttata, vena cellulas duas separante basi alboflavescente, abdomine lateribus ad angulos basales segmentorum macula flava notato. Caput pronoto paullo brevius, antennis obscure ferrugineis, articulis duobus primis subaequalibus, tertio secundo vix dimidio longiore. Pronotum fere in medio transversim impressum, impressionibus lobi antici distinctis, lobo postico laevi, marginibus lateralibus posticis rectis. Hemelytra apicem abdominis paullum superantia. Abdomen subtus nitidum, segmento genitali maris apice rotundato, spinis duabus distantibus paullo divaricatis armato. Pedes nigri, tibiis piceis, tarsis, apice excepto, ferrugineis. - Long. of 11,4 mill.

Mexico. - Ad divisionem c Ståli referendus.

Nalata squalida n. sp. - Nigra, capite superne, tuberculis lobi antici pronoti, pectore hic et illic, summo apice scutelli, macula obsoleta pone hujus apicem, ima basi areae interioris membranae, macula laterali segmentorum ventralium, segmentis connexivi postice lobisque apicalibus abdominis obscure lutescentibus. Caput subtus granulis sex setiferis luteis biseriatim positis armatum, granulis duobus anticis a posterioribus remotis, rostro nigro, apicem versus piceo, macula superiore pallida prope apicem articuli primi, antennarum articulis duobus primis nigris, dimidio basali articuli primi fusco-luteo, articulo secundo pilis longis parce vestito, (art. ultimi desunt). Pronotum latitudine basali brevius, basi quam apice triplo et dimidio 
latius, lobo antico rugis duabus bituberculatis antrorsum convergentibus instructo, tuberculis posterioribus altis, extus oblique sulcatis, inter carinas profunde sulcato, sulco per lobum posticum continuato et ibidem dilatato, lobo postico utrinque obsolete carinato, intra angulos laterales impresso, marginibus lateralibus posticis vix dilatatis ad angulos basales scutelli non nisi obsoletissime prominulis. Venter medio deplanatus, lobis apicalibus lateralibus magnis, rotundatis, apice subcontiguis. Pedes nigri, macula antica femorum anteriorum, annulis duobus tibiarum anteriorum et femorum posticorum, tibiis posticis (annulis duobus nigris exceptis) basique tarsorum omnium luteis; femora aspere granulata. - Long. \& 12 mill.

Columbia (Ocana).

Ceteris speciebus fere duplo major et variis notis distincta.

\section{Description d'un Eumolpide nouveau du Sahara algérien [CoL.]}

Par le $\mathrm{D}^{\mathrm{r}} \mathrm{A}$. Chobaut.

Ghloropterus pallidus n. sp. - Allongé, parallèle sur les còtés, peu convexe, glabre, luisant, avec la tète, le pronotum, la suture élytrale et le dessous roussâtres, les élytres, les antennes et les pattes jaunầtres. Tète brillante, grossièrement ponctuée, avec une carène sur le vertex. Yeux très gros, très saillants, ne laissant entre eux qu’un intervalle guère plus large que n'est long le dernier article antennaire. Antennes dépassant le milieu du corps, entièrement jaunàtres. Pro. notum transverse, convexe, rebordé à la base et sur les còtés, plus atténué en arrière qu'en avant, anguleusement arrondi sur les côtés, avec les angles antérieurs fortement infléchis vers le bas, presque droits, les postérieurs obtus, couvert d'une ponctuation forte et assez dense, orné d'une petite tache ronde, noiràtre, vers le milieu des còtés, à quelque distance du bord. Écusson allongé, arrondi au sommet, très lisse. Élytres allongés, plus larges que le prothorax, à épaules rondes, saillantes, à còtés subparallèles et rebordés, arrondis ensemble à l'extrémité, munis à la base de 11 lignes de points fins, peu régulièrement disposés, s'évanouissant vers l'apex; la $1^{\text {re }}$ (à partir de la suture) réunie à la $2^{\mathrm{e}}$ en dessous de l'écusson, la $10^{\mathrm{e}}$ à la $11^{\mathrm{e}}$ en dessous de l'épaule, la 8 e subdivisée en 2 ou 3 séries au-dessous de la saillie humérale. Pattes finement pubescentes, fémurs antérieurs avec une forte dent, tibias postérieurs échancrés en dehors vers l'extrémité. - Long. 4 mill. 


\section{$2 \mathrm{BHL}$ Biodiversity Heritage Library}

Bergroth, Ernest Evald. 1898. "Description de deux Réduviides nouveaux [Hémipt.]." Bulletin de la Société entomologique de France 1898, 307-308.

View This Item Online: https://www.biodiversitylibrary.org/item/38046

Permalink: https://www.biodiversitylibrary.org/partpdf/78626

\section{Holding Institution}

Smithsonian Libraries

\section{Sponsored by}

Smithsonian

\section{Copyright \& Reuse}

Copyright Status: NOT_IN_COPYRIGHT

This document was created from content at the Biodiversity Heritage Library, the world's largest open access digital library for biodiversity literature and archives. Visit BHL at https://www.biodiversitylibrary.org. 